\title{
Reading from an LCD monitor versus paper: Teenagers' reading performance
}

\author{
Kim, Hak Joon $\bowtie$ \\ Southern Connecticut State University, USA (kimh1@ southernct.edu)
}

Kim, Joan

School of Human Ecology, Cornell University, USA (jk2355@cornell.edu)

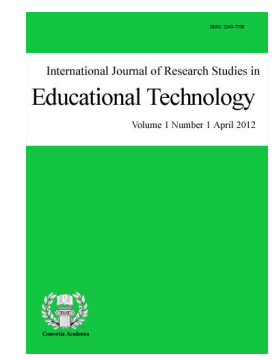

ISSN: $2243-7738$ Online ISSN: 2243-7746

\section{Abstract}

The purpose of the study was to examine differences in reading performance when an electronic test format with a scrolling text mode on a LCD monitor and a traditional paper test format were used to present reading tests to teenagers who belong to Generation Z. In this study, participants were 108 high school students who each read two different reading passages, one from paper and the other from an LCD monitor. The results show that teenagers' reading performance is affected by a presentation medium. Teenagers scored significantly higher on the paper reading comprehension tests than on the electronic ones, with average scores of 76 and 61 respectively. In addition, teenagers took much longer time to read passages and answer questions on the electronic tests than the paper tests. The paper tests only took teenagers an average of 10 minutes, but the electronic tests took an average of 16 minutes to complete. Several other variables such as gender and presentation medium preference were also tested against the variables of reading performance. These findings have strong implications for educators and educational administrators.

Keywords: reading comprehension; reading speed; computer-based assessment; human computer interaction; educational technology 


\section{Reading from an LCD monitor versus paper: Teenagers' reading performance}

\section{Introduction}

Improvements in computer and communication technologies have encouraged the delivery of educational tests through computers. Although computer-based test administration has the potential to save time, resources, and money, an important question that arises when tests are administered in both formats is whether or not the scores produced are comparable. A large body of research has been done to examine the impact of transitioning passage-based reading tests from paper to computer over the last several decades.

There have been many studies comparing the effects of computer versus printed presentation of text especially on reading speed and comprehension. A substantial body of research reported that people read more slowly from screens than from paper. Muter, Latremouille, Treurniet, and Beam (1982) had 32 subjects read continuous text for two hours, with half of the subjects reading from a videotext terminal and the other half from a book. They found that subjects in the book condition read at a rate of 222 words per minute, whereas subjects in the video condition read at a rate of 159 words per minute. That is, subjects read $28 \%$ slower in the video condition than in the book condition. In the Gould and Grischkowsky (1984) experiment, 24 people proofread excerpts from newspaper and magazine articles for misspellings. Although the format of the material was exactly the same on the CRT and on paper, participants proofread significantly more slowly on CRTs than on paper (159 words versus 205 words per minute, that is $22 \%$ slower). These findings were supported in a number of other later studies (Kruk \& Muter, 1984; Gould et al., 1987; Leventhal, Teasley, Instone, Rohlman, \& Farhat, 1993; Martin \& Platt, 2001; Kerr \& Symons, 2006).

Leventhal, Teasley, Instone, Rohlman, and Farhat (1993) examined readers locating information in an encyclopedia presented on a computer screen and on paper. They reported that screen readers were on average $15 \%$ slower than paper readers. A recent experimental study by Kerr and Symons (2006) compared the effect of computer and paper presentation of text on reading time. Participants were 60 grade five students, who each read two expository texts, one in a print format and the other from a computer monitor, which used a scrolling text interface. Children read text more slowly on computer monitors than on paper. This is consistent with previous studies with adults reporting slower reading times from computer screens. Even though figures vary according to means of calculation and experimental design (Dillion, 1994), the findings of the studies suggest that reading from a screen is a $15-30 \%$ slower than reading from paper.

On the other hand, several other studies (Askwall, 1985; Cushman, 1986; Muter \& Maurutto, 1991; Holzinger et al., 2011) reported no reading speed difference between screens and paper. In the Cushman (1986) experiment, 76 subjects read continuous text for 80 minutes using microfiche, video display terminals and printed paper copy. A minimum of two days of rest was given between sessions. The Cushman study found that the difference between mean reading speeds for video display terminals and paper copy was not statistically significant. Muter and Maurutto (1991) conducted two experiments to test difference in reading speed between a CRT and a book. In the first and second experiments, 24 and 18 adult subjects were respectively tested. The subjects were allowed to hold the book in whatever manner they preferred and to adjust their distance from the screen. The results of the two different experiments indicated no significant differences between reading from a CRT versus reading from a book.

In a very recent study, Holzinger et al. (2011) conducted an experiment with 111 medical professionals, working in a real-life setting. The participants were each asked to read diagnosis reports, a gynecological report and an internal medical document on both an LCD monitor and paper in a randomly assigned order. The results of the study showed no significant difference in reading speed between an LCD versus paper. Gould et al. (1987) note, some of these experiments is open to explanations but "the evidence on balance ... indicates that the basic 
finding is robust - people do read more slowly from CRT displays" (p. 269). Because a number of intervening variables, such as the size of character fonts and screen resolution may have contaminated the results and complicate their interpretation, however, Dillon (1994) asserts that "the evidence surrounding the argument for a speed deficit in reading from VDUs is less than conclusive" (p. 31).

Determining whether computer presentation of text affects reading comprehension would be more difficult than the question of reading speed due to the difficulty of devising a suitable means of quantification. Nonetheless, many studies on the effect of presentation medium on reading comprehension have been conducted since 1980s. Most of the studies (Muter, Latremouille, Treurniet, \& Beam, 1982; Kruk \& Muter, 1984; Cushman, 1986; Feldmann \& Fish, 1987; Muter \& Maurutto, 1991; McKnight, Dillon, Ricardson, Haraldsson, \& Spinks, 1992; Pommerich, 2004; Higgins, Russell, \& Hoffmann, 2005; Baker, 2010; Holzinger et al., 2011) have reported no significant reading comprehension differences between the two media. Muter, Latremouille, Treurniet, and Beam (1982) required 32 subjects to answer 25 multiple-choice questions after reading text for two hours, with half of the subjects reading from a videotext terminal and the other half from a book. They found that condition (video versus book) had no effect on comprehension scores.

Kruk and Muter (1984) compared two video conditions (one was a delayed condition and the other was an instant condition) with two book conditions (one with 60 and the other with 39 characters per line). Each of 24 subjects read text in all four conditions. For reading comprehension, there were no significant differences between conditions. Cushman (1986) required 76 subjects to read continuous text for 80 minutes using microfiche, video display terminals and printed paper copies. Reading comprehension scores were obtained by calculating the percentage of correct answers for selected reading comprehension questions administered at the end of each 80-minute reading session. Reading comprehension scores were similar for all conditions. McKnight, Dillon, Ricardson, Haraldsson, and Spinks (1992) compared reading comprehension by assessing subjects' written essays. Subjects were graduate students and they were asked to take notes while they read passages on a screen or from a book. Based upon the notes, the students wrote essays and the essays were marked by an expert in the field. The study reported no significant comprehension difference between the two media.

Higgins, Russell, and Hoffmann (2005) examined the impact of transitioning fourth grade reading comprehension assessments to the computer. In the experimental study, 219 fourth graders were randomly assigned to take a one-hour reading comprehension assessment on paper, on a computer using scrolling text to navigate through passages, or on a computer using paging text to navigate through passages. They found that there were no significant differences in reading comprehension scores across testing modes. A similar result was found by Holzinger et al. (2011) in their study with 111 medical professionals. The participants were asked to read diagnosis reports, a gynecological report and an internal medical document on both an LCD and paper in a randomly assigned order. Reading comprehension was measured by the Chunked Reading Test. Again, they found no significant difference in reading comprehension between an LCD versus paper.

In contrast to these studies, several studies have questioned the comparability of reading comprehension scores when passages and test items are displayed on a computer screen versus paper (Olsen, Maynes, Slawson, \& Ho, 1989; Choi \& Tinkler, 2002; Pomplun \& Custer, 2005; Kerr \& Symons, 2006). Choi and Tinkler (2002) evaluated the comparability of computerized and paper versions of state reading assessments. They found that reading tests were harder for third graders when presented on computer screens than on paper. Pomplun and Custer (2005) investigated the equivalence of scores from computerized and paper formats of a series of K-3 reading screening tests. The results indicated that the computerized format produced lower scores than the paper format across all four grades. In the Kerr and Symons (2006) experimental study, which compared the effect of computer and paper presentation of text, 60 grade five students were required to read two expository texts, one in a print format and the other from a computer monitor, which used a scrolling text interface. The study found that children were more efficient at comprehending text when reading from paper.

Conflicting results have been found in previous studies on whether reading speed and reading 
comprehension scores differ between computer and paper presentations of the same reading tests. Since the results of these studies are inconsistent and the use of computers in educational settings has exploded in recent years, it would be even more important to examine whether computer presentation of reading passages really affects reading performance. Moreover, most of the previous research that has examined reading differences between computer and paper presentation has studied either adult or children populations. Little research has been done on teenagers' reading performance on the two media formats.

Teenagers today belong to Generation Z (people born from the mid 1990s to 2010). The main characteristics of Generation $\mathrm{Z}$ are that they are highly connected and adept at multi-tasking. They are true digital natives and have not known a life without personal computers, the Internet, text messaging, MP3 players, smartphones, and social networking (Pupedis \& Bellman, 2011). They are both comfortable with and dependent on computer and communication technologies. Teenagers who are accustomed to using the Internet or reading text passages on a computer may find scrolling through a reading passage to be a natural process. The purpose of the study is to examine differences in reading performance when an electronic test format with a scrolling text mode on a LCD monitor and a traditional paper test format were used to present reading tests to teenagers who belong to Generation Z.

\section{Method}

\subsection{Subjects}

The subjects of the study consisted of 108 senior high school students (51 male and 57 female students) at one affluent suburban public high school in Connecticut. All subjects were grade eleven students at the Advanced Placement class level. Every student in the grade at the school's Advanced Placement class level participated in the study with the exception of 12, who declined to participate. Class time was utilized to administer the study. Each student that opted to participate in the study was compensated with a late homework pass and a treat.

\subsection{Materials}

There were two reading comprehension tests (A and B) that were administered to the subjects. The two tests were taken from outdated SAT English reading comprehension tests, virtually the same in length and difficulty. Tests A and B were both passages on similar topics in the subject of American history. Both versions A and B of the tests printed on $81 / 2$ " $\times 11$ " paper consisted of two pages stapled together with the reading passage first and 10 multiple-choice questions following. The electronic tests A and B were scanned versions of the printed tests and could be viewed from beginning to end by scrolling on a 17-inch high-resolution LCD monitor. Pixel dimensions of the monitor were $1280 \times 1024$, and it had a refresh rate of $60 \mathrm{~Hz}$. All versions of the tests were to be answered by circling the correct multiple-choice answer, whether it was with a pencil or with the mouse.

In addition to the reading comprehension tests, there was a short paper-printed survey regarding test presentation mode preference and computer experience. After the completion of the final experimental test, the 108 teenagers completed the following five-item survey: (a) In order to take a reading comprehension test, which medium would you choose? (b) How comfortable do you feel with using a computer? (c) How comfortable do you feel with using a computer mouse? (d) How comfortable do you feel with scrolling text to navigate through passages? and (e) How often do you use the Internet / World Wide Web?

\subsection{Procedure}

The testing took place in two quiet and isolated rooms, simulated to be actual SAT test settings. Printed-paper versions of tests A and B were administered in one room and scanned-in electronic versions of the two tests on an LCD monitor in the other room. Each of the subjects took two different reading comprehension 
tests, Test A and Test B through two different modes of presentation, printed-paper versus on an LCD monitor. The subjects were randomly assigned the order of tests A and B and the presentation mode through which they would be administered in order to eliminate any form of bias in testing. Overall, there were four different groups of test-takers: (a) Paper test A then LCD test B, (b) Paper test B then LCD test A, (c) LCD test A then Paper test B, and (d) LCD test B then Paper test A.

Directions were administered to the subjects in each room before the start of each test. The students were instructed to read the passages and answer the corresponding multiple-choice questions. The subjects taking the paper-and-pencil tests were instructed to circle the letter next to the answer they believed to be correct, and a demonstration was also shown. The subjects taking the tests on LCD monitors were given the same instructions and were shown how to do so with a computer mouse. All subjects were also instructed to use a pencil or computer mouse to underline or mark the reading passages as desired. All subjects were informed that there was no time limit and could hand in their tests whenever they felt they were done. As each test was completed, all completion times were recorded. After taking one test through one presentation mode, the subjects were given ten-minute breaks before proceeding to the next test on a different mode. After the completion of the final experimental test, the subjects were administered a short survey about preferences on the presentation mode of tests and basic computer experience. The reading comprehension tests were evaluated based on the percentage of multiple-choice questions answered correctly.

\section{Results}

Table 1 shows descriptive statistics for reading speed by the presentation medium. Teenagers took much longer time to read passages and answer questions on the electronic tests than on the paper tests. Teenagers spent an average of 15.61 minutes reading text on LCD monitors, which is $36 \%$ slower, when compared to an average of 9.98 minutes reading text on paper. A paired-samples t-test showed that teenagers read text significantly more slowly on LCD monitors than on paper with $\mathrm{t}(107)=18.01, p=.000$.

\section{Table 1}

Descriptive statistics for reading speed by presentation medium

\begin{tabular}{lccccc}
\hline \multicolumn{1}{c}{ Presentation Medium } & $N$ & Minimum & Maximum & Mean & $S D$ \\
\hline LCD & 108 & 12.00 & 22.00 & 15.61 & 2.50 \\
Paper & 108 & 6.00 & 18.00 & 9.98 & 2.78 \\
\hline
\end{tabular}

The average score on all the reading comprehension tests was 68.08 points. Teenagers scored much higher on the paper reading comprehension tests than on the electronic ones, with average scores of 75.67 and 60.50 respectively (see Table 2). There was a more than 15 point difference in the mean scores between the LCD and Paper groups. A paired-samples t-test indicated that there was a statistically significant difference in reading comprehension scores between the two test presentation media groups with $\mathrm{t}(107)=-12.34, p=.000$.

\section{Table 2}

Descriptive statistics for reading comprehension by presentation medium

\begin{tabular}{lccccc}
\hline \multicolumn{1}{c}{ Presentation Medium } & $N$ & Minimum & Maximum & Mean & $S D$ \\
\hline LCD & 108 & 11.00 & 100.00 & 60.50 & 23.97 \\
Paper & 108 & 17.00 & 100.00 & 75.67 & 21.25 \\
\hline
\end{tabular}

As seen in Table 3, 91 (almost 85\%) of the 108 teenagers preferred a paper medium for their reading tests to an LCD medium. Among female teenagers, 93\% preferred a paper medium for their reading tests while nearly $75 \%$ of the male teenagers preferred a paper medium to an LCD medium. A chi-square analysis, $\chi^{2}(1, N=108)$ $=6.925, p<.01$, revealed that there was a significant gender difference in the preference for electronic or paper reading tests. Significantly more female teenagers preferred a paper medium for their reading tests to an LCD 
Kim, H. J. \& Kim, J.

medium than did male teenagers.

Table 3

Gender differences in preferences for different test media

\begin{tabular}{lccc}
\hline \multirow{2}{*}{ Gender } & \multicolumn{2}{c}{ Medium Preference } & Total \\
\cline { 2 - 3 } & LCD & Paper & \\
\hline Female & $4(7.0 \%)$ & $53(93.0 \%)$ & $57(100 \%)$ \\
Male & $13(25.5 \%)$ & $38(74.5 \%)$ & $51(100 \%)$ \\
\hline Total & $17(15.7 \%)$ & $91(84.3 \%)$ & $108(100 \%)$ \\
\hline
\end{tabular}

To examine whether the effect of presentation medium differed for female and male teenagers, reading speed was compared between gender within and across each presentation medium (see Table 4). Overall female teenagers took a little longer time to read text on both the LCD monitor and paper than male teenagers. However, these differences were very small and not statistically significant.

\section{Table 4}

Descriptive statistics for $L C D$ and paper reading speed by gender

\begin{tabular}{lllccc}
\hline \multirow{2}{*}{ Gender } & $N$ & \multicolumn{2}{c}{ LCD Reading Speed } & \multicolumn{2}{c}{ Paper Reading Speed } \\
\cline { 3 - 6 } & & Mean & $S D$ & Mean & $S D$ \\
\hline Female & 57 & 16.04 & 2.73 & 10.11 & 2.70 \\
Male & 51 & 15.14 & 2.15 & 9.84 & 2.89 \\
\hline
\end{tabular}

Table 5 shows that overall female teenagers earned higher reading comprehension test scores on both electronic and paper tests than did male teenagers. Female teenagers received average scores of 62.18 and 79.07 on the electronic and paper tests respectively. On the other hand, male teenagers received average scores of 58.63 and 71.86 on the electronic and paper tests respectively. However, the differences between their reading comprehension scores on each of the two different media were not statistically significant.

Table 5

Descriptive statistics for $L C D$ and paper reading comprehension by gender

\begin{tabular}{lccccc}
\hline \multirow{2}{*}{ Gender } & \multirow{2}{*}{$N$} & \multicolumn{2}{c}{ LCD Reading Comprehension } & \multicolumn{2}{c}{ Paper Reading Comprehension } \\
\cline { 3 - 6 } & & Mean & $S D$ & Mean & $S D$ \\
\hline Female & 57 & 62.18 & 22.46 & 79.07 & 21.47 \\
Male & 51 & 58.63 & 25.65 & 71.86 & 20.55 \\
\hline
\end{tabular}

As shown in Table 6, the vast majority (91) of the teenagers preferred a paper medium for their reading tests to an LCD medium while only 17 of them preferred an LCD medium. Without regard to their preferences, however, there were virtually no differences between the LCD and paper-preferred teenager groups in reading speed on both the LCD and paper media.

\section{Table 6}

Descriptive statistics for $L C D$ and paper reading speed by medium preference

\begin{tabular}{lccccc}
\hline Medium Preference & $N$ & \multicolumn{2}{c}{ LCD Reading Speed } & \multicolumn{3}{c}{ Paper Reading Speed } \\
\cline { 3 - 6 } & & Mean & $S D$ & Mean & $S D$ \\
\hline LCD-Preferred Teenagers & 17 & 15.71 & 2.23 & 9.41 & 1.70 \\
Paper-Preferred Teenagers & 91 & 15.59 & 2.56 & 10.09 & 2.93 \\
\hline
\end{tabular}

Teenagers who preferred a paper medium for their reading tests to an LCD medium earned higher reading 
comprehension test scores on both the electronic and paper tests (see Table 7). Paper-preferred teenagers received average scores of 61.59 and 79.30 on the electronic and paper tests respectively while LCD-preferred teenagers received average scores of 54.65 and 56.24 respectively on the two tests. When the reading comprehension tests were done on the LCD monitor, there was no significant medium preference effect on the reading comprehension scores of the two LCD-preferred and paper-preferred groups $\mathrm{t}(18.33)=.795, p=.437$. However, there was a statistically significant medium preference effect on the reading comprehension scores of the two groups $\mathrm{t}(19.37)=3.614, p=.002$ when the reading comprehension tests were done on paper. Those who preferred a paper medium for their reading tests to an LCD medium received significantly higher reading comprehension scores than did LCD-preferred teenagers when the reading comprehension tests were done on paper.

\section{Table 7}

Descriptive statistics for $L C D$ and paper reading comprehension by medium preference

\begin{tabular}{lccccc}
\hline Medium Preference & $N$ & \multicolumn{2}{c}{ LCD Reading Comprehension } & \multicolumn{2}{c}{ Paper Reading Comprehension } \\
\cline { 3 - 6 } & & Mean & $S D$ & Mean & $S D$ \\
\hline LCD-Preferred Teenagers & 17 & 54.65 & 34.83 & 56.24 & 25.07 \\
Paper-Preferred Teenagers & 91 & 61.59 & 21.44 & 79.30 & 18.45 \\
\hline
\end{tabular}

\section{Discussions}

The primary purpose of the present study was to examine differences in reading performance when an electronic test format with a scrolling text mode on a LCD monitor and a traditional paper test format were used to present reading tests to teenagers who belong to Generation Z. A vast majority of the teenagers preferred traditional paper tests for their reading comprehension tests to electronic tests on LCD monitors. This is contrary to a number of previous studies reporting that the majority of students indicated they would prefer to test on computer (Wang, Young, \& Brooks, 2004; Higgins, Russell, \& Hoffmann, 2005; Kingston, 2009). In addition, the present study found that significantly more female teenagers preferred a paper medium for their reading comprehension tests to an LCD medium than did male teenagers. Previous research reporting a gender gap in computer use has suggested that females have more negative attitudes towards computers than do males (Chen, 1987; Clarke, 1990; Bannert \& Arbinger, 1996; Comber, Colley, Hargreaves, \& Dorn, 1997; Todman, 2000; Broos, 2005; Horne, 2007). Contrary to all expectations that gender differences would disappear over time with an increase in familiarity of females with computers, these differences have been repeatedly reported in many research studies over the last few decades. The results of the present study further support previous studies reporting that males have more positive attitudes towards computers and more interest in computer-related activities than do females.

Another major finding is that teenagers read text passages significantly more slowly on LCD monitors than on paper. This finding is generally consistent with previous studies reporting slower reading times from computer screens (Muter, Latremouille, Treurniet, \& Beam, 1982; Gould \& Grischkowsky, 1984; Kruk \& Muter, 1984; Gould et al., 1987; Leventhal, Teasley, Instone, Rohlman, \& Farhat, 1993; Martin \& Platt, 2001; Kerr \& Symons, 2006). However, a $36 \%$ slower reading speed on LCD monitors is even worse than the findings of the previous studies that reported a $15-30 \%$ slower reading speed when reading from a computer screen relative to paper.

A number of earlier studies, which reported differences in reading speed between the two media, suggested that poor display qualities of computer screens are most likely responsible for the reading speed deficit (Gould \& Grischkowsky, 1984; Gould et al., 1987; Muter \& Maurutto, 1991). Therefore, they presumed that people can read as fast from computer screens as from paper if text passages are presented on high display quality screens. Although high-resolution LCD monitors that have greatly increased the legibility of the earlier computer screens were used for the reading tests in the present study, teenagers still read text passages significantly more slowly 
on LCD monitors. The results of the study indicate that the display qualities of computer monitors would not be a single key factor that affects slower reading speeds. The reading speed difference may be due to a combination of visual, cognitive, and emotional variables.

Teenagers scored significantly higher on the paper reading comprehension tests than on the electronic ones. The results of the study further support the findings of the previous studies reporting that people were more efficient at comprehending text when reading from paper (Olsen, Maynes, Slawson, \& Ho, 1989; Choi \& Tinkler, 2002; Pomplun \& Custer, 2005; Kerr \& Symons, 2006). With regard to difficulties in reading from computers, some researchers proposed that a scrolling presentation of text may disrupt readers' structural representation of the text (Eklundh, 1992; Piolat, Roussey, \& Thunin, 1997; Choi \& Tinkler, 2002; Pommerich, 2004; Higgins, Russell, \& Hoffmann, 2005; Kerr \& Symons, 2006). As a result, therefore, they further proposed that scrolling text may negatively impact students' reading comprehension test scores in passage based assessments.

Although almost all of the teenagers in the present study felt that they were very comfortable with scrolling text to navigate through passages, the results of the study indicate that the teenagers may be still disadvantaged by the scrolling text mode. Reading while scrolling text would be cognitively different than reading a whole page. To address the issue of a scrolling text interface, several previous studies (Pommerich, 2004; Higgins, Russell, \& Hoffmann, 2005) compared a scrolling text interface to a page-by-page interface on computers and found that students generally performed worse under the scrolling condition than the whole page condition. Because the findings of these studies were not statistically significant, however, the evidence surrounding the argument for the disadvantage of using a scrolling text interface is far from conclusive. Further research is necessary to address the issue of a scrolling text interface.

Then why do teenagers, who belong to Generation Z, have difficulty testing on an LCD monitor? Although teenagers are well accustomed to the computer and communication technologies, they would mostly use those technologies in relaxed leisure settings. The teenagers are not used to having to concentrate and focus on content matter in the way that they would have to do for reading comprehension tests. To understand what factors really affect teenagers' poor reading performance on LCD monitors, further research into the causal factors is needed.

\section{Conclusion and recommendations}

The results of the study show that almost all of the teenagers who belong to Generation $\mathrm{Z}$ felt that they were very comfortable with using computers. When they were asked to take reading comprehension tests, however, most of the teenagers preferred a traditional paper test to an electronic test on an LCD monitor. In particular, significantly more female teenagers preferred a paper medium for their reading tests to an LCD medium than did male teenagers. Teenagers' reading performance was significantly more effective on paper tests than on electronic tests. Teenagers read text passages significantly faster on paper than on LCD monitors. They received significantly higher reading comprehension scores on paper tests than on electronic tests. The results of the study indicate that the medium by which text passages are presented could influence teenagers' reading performance.

These findings have strong implications for educators and educational administrators. The results suggest that states should introduce standardized electronic tests such as SAT test more cautiously at the high school levels especially when it comes to testing for reading comprehension. Before standardized electronic tests are implemented, there should be a transition period from the paper test to the electronic test. During the transition period, the teenagers should be allowed to choose either one of the two test formats according to their test medium preferences. Until scores obtained from both test formats are comparable, standardized reading comprehension tests should be administered in both formats.

In light of the current technological explosion in educational settings, it is important to continue research in this area so that we can better understand how reading and comprehending are affected by a presentation medium. The results of the research are from a small-scale experimental study. Future research should be conducted on a larger and more diverse sample of teenagers. In addition, the number of text passages and test items should be 
increased. Further large-scale experimental studies examining the effect of a test medium on teenagers' reading performance are necessary to establish the generalizability of the findings of the study.

Moreover, the use of mobile handheld devices such as smartphones and tablet computers has become pervasive in our lives. More and more people read text on the small screens of these handheld devices on a daily basis, and they may open new possibilities for reading applications in education. However, little research has been done on reading performance and behavior on a small screen. In particular, it would be critical to investigate and understand differential effects when comparing reading performance and behavior on a small screen and a larger screen. The evolving designs of mobile handheld devices that can be used to read text will benefit from the new research.

\section{References:}

Askwall, S. (1985). Computer supported reading vs reading text on paper: a comparison of two reading situations. International Journal of Man-Machine Studies, 22, 425-439. <http://dx.doi.org/10.1016/S0020-7373(85)80048-1>

Baker, R. D. (2010). Comparing the readability of text displays on paper, e-book readers, and small screen devices. Unpublished Doctoral dissertation, University of North Texas.

Bannert, M., \& Arbinger, P. R. (1996). Gender-related differences in exposure to and use of computers: Results of a survey of secondary school students. European Journal of Psychology of Education, 11, 269-282. $<$ http://dx.doi.org/10.1007/BF03172940>

Broos, A. (2005). Gender and information and communication technologies (ICT) anxiety: Male self-assurance and female hesitation. CyberPsychology \& Behavior, 8(1), 21-31. $<$ http://dx.doi.org/10.1089/cpb.2005.8.21>

Chen, M. (1987). Gender differences in adolescents' uses of and attitudes toward computers. In M. L. McLaughlin (Ed.), Communication yearbook (pp. 200-216). London: Sage.

Choi, S. W., \& Tinkler, T. (2002). Evaluating comparability of paper-and-pencil and computer-based assessment in a K-12 setting. Paper presented at the annual meeting of the National Council on Measurement in Education, New Orleans, LA.

Clarke, V. A. (1990). Sex differences in computing participation: concerns, extent, reasons and strategies. Australian Journal of Communication, 34, 52-66.

Comber, C., Colley, A., Hargreaves, D. J., \& Dorn, L. (1997). The effects of age, gender and computer experience upon computer attitudes. Educational Research, 39(2), 123-133. $<$ http://dx.doi.org/10.1080/0013188970390201>

Cushman, W. H. (1986). Reading from microfiche, VDT and the printed page: Subjective fatigue and performance, Human Factors, 28(1), 63-73.

Dillon, A. (1994). Designing usable electronic text: Ergonomic aspects of human information usage. London, England: Taylor \& Francis. <http://dx.doi.org/10.4324/9780203470343>

Eklundh, K. S. (1992), Problems in achieving a global perspective of the text in computer-based writing. Instructional Science, 21, 73-84. <http://dx.doi.org/10.1007/BF00119656>

Feldmann, S. C., \& Fish, M. C. (1987). Reading comprehension of high school students on print vs. microcomputer-generated text. Retrieved July 3, 2012, from http://ww.eric.ed.gov/contentdelivery/servlet/ERICServlet?accno=ED282175

Gould, J. D., \& Grischkowsky, N. (1984). Doing the same work with hard copy and cathode-ray tube (CRT) computer terminals. Human Factors, 26(3), 323-337.

Gould, J. D., Alfaro, L., Barnes, V., Finn, R., Grischkowsky, N., \& Minuto, A. (1987). Reading is slower from CRT displays than from paper: Attempts to isolate a single-variable explanation. Human Factors, 29(3), 269-299.

Higgins, J., Russell, M., \& Hoffmann, T. (2005). Examining the effect of computer-based passage presentation on reading test performance. Journal of Technology, Learning, and Assessment, 3(4). Retrieved July 3, 2012, 
Kim, H. J. \& Kim, J.

from http://ejournals.bc.edu/ojs/index.php/jtla/article/view/1657/1499

Holzinger, A., Baernthaler, M., Pammer, W., Katz, H., Bjelic-Radisic, V., \& Jiefle, M. (2011). Investigating paper vs. screen in real-life hospital workflows: Performance contradicts perceived superiority of paper in the user experience. International Journal of Human-Computer Studies, 69(9), 563-570.

$<$ http://dx.doi.org/10.1016/j.ijhcs.2011.05.002>

Horne, J. (2007). Gender differences in computerized and conventional educational tests. Journal of Computer Assisted Learning, 23, 47-55. <http://dx.doi.org/10.1111/j.1365-2729.2007.00198.x>

Kerr, M. A., \& Symons, S. E. (2006). Computerized presentation of text: Effects on children's reading of informational material. Reading and Writing, 19(1), 1-19. $<$ http://dx.doi.org/10.1007/s11145-003-8128-y>

Kingston, N. M. (2009). Comparability of computer- and paper-administered multiple-choice tests for K-12 populations: a synthesis. Applied Measurement in Education, 22, 22-37. $<$ http://dx.doi.org/10.1080/08957340802558326>

Kruk, R. S., \& Muter, P. (1984). Reading continuous text on video screens, Human Factors, 26(3), 339-345.

Leventhal, L., Teasley, B., Instone, K., Rohlman, D., \& Farhat, J., (1993). Sleuthing in HyperHolmes: an evaluation of using hypertext versus a book to answer questions. Behaviour \& Information Technology, 12(3), 149-164. <http://dx.doi.org/10.1080/01449299308924376>

Martin, L. A., \& Platt, M. W. (2001). Printing and screen reading in the medical school curriculum: Guttenberg vs. the cathode ray tube. Behaviour \& InformationTechnology, 20(3), 143-148. $<$ http://dx.doi.org/10.1080/01449290110048043>

McKnight, C., Dillon, A., Ricardson, J., Haraldsson, H., \& Spinks, R. (1992). Information access in different media: an experimental comparison. In E. J. Lovesey (Ed.) Contemporary Ergonomics 1992 (pp. 515-519). London, England: Taylor and Francis.

Muter, P., Latremouille, S. A., Treurniet, W. C., \& Beam, P. (1982). Extended reading of continuous text on television screens. Human Factors, 24(5), 501-508.

Muter, P., \& Maurutto, P. (1991). Reading and skimming from computer screens and books: the paperless office revisited. Behaviour \& Information Technology, 10(4), 257-266.

$<\underline{\text { http://dx.doi.org/10.1080/01449299108924288> }}$

Olsen, J. B., Maynes, D. D., Slawson, D., \& Ho, K. (1989). Comparsion of paper-administered, computer-administered and computerized adaptive achievement tests. Journal of Educational Computing Research, 5, 311-326. <http://dx.doi.org/10.2190/86RK-76WN-VAJ0-PFA3>

Piolat, A., Ropussey, J., \& Thunin, O. (1997). Effects on screen presentation on text reading and revising. International Journal of Human-Computer Studies, 47, 565-589. $<$ http://dx.doi.org/10.1006/ijhc.1997.0145>

Pommerich, M. (2004). Developing computerized versions of paper-and-pencil test: Some mode effects for passage-based tests. Journal of Technology, Learning, and Assessment, 2(6). Retrieved July 3, 2012, from http://ejournals.bc.edu/ojs/index.php/jtla/article/view/1666/1508

Pomplun, M., \& Custer, M. (2005). The score comparability of computerized and paper-and-pencil formats for K-3 reading tests. Journal of Educational Computing Research, 32(2), 153-166. $<$ http://dx.doi.org/10.2190/D2HU-PVAW-BR9Y-J1CL>

Pupedis, G., \& Bellman, C. (2011). Shove over Gen Y: Gen Z is almost here. Proceedings of the Surveying \& Spatial Sciences Biennial Conference 2011, 21-25 November 2011, Wellington, New Zealand, pp. 331-339.

Todman, J. (2000). Gender differences in computer anxiety among university entrants since 1992. Computers and Education, 34, 27-35. <http://dx.doi.org/10.1016/S0360-1315(99)00036-6>

Wang, S., Young, M., \& Brooks, T. (2004). Administration mode comparability study for Stanford Diagnostic Reading and Mathematics Tests. San Antonio, TX: Harcourt. 